\title{
The Law of Self-Replication and the Birth of Life Science
}

\section{Muying Zhou}

The Central Hospital of Shandong Feicheng Coal-Mining Group Corporation, Feicheng, China

Email:fckzmy@sina.com

How to cite this paper: Zhou, M.Y. (2018) The Law of Self-Replication and the Birth of Life Science. Open Access Library Journal, 5: e4644.

https://doi.org/10.4236/oalib.1104644

Received: May 7, 2018

Accepted: June 4, 2018

Published: June 7, 2018

Copyright $\odot 2018$ by author and Open Access Library Inc.

This work is licensed under the Creative Commons Attribution International License (CC BY 4.0).

http://creativecommons.org/licenses/by/4.0/

\begin{abstract}
The understanding of the unique replication facts of living things helps us to discover the basic law of the life world: the law of self-replication. This law reveals the root causes of life arising and lays the foundation stone for life science. From now on, what is a living thing, what does life mean? There has been a standard (the definition).
\end{abstract}

\section{Subject Areas}

Molecular Biology, Microbiology, Mathematical Biology, Algebra

Keywords

Life, Replication, Law, Self-Replication

\section{Introduction}

Some important and basic law often looks like a tautology or self-evident to nonsense rubbish, such as " $\mathrm{A}=\mathrm{A}$ " (the law of identity) and " $\mathrm{F}=-\mathrm{F}$ " (Newton's third law of motion). This seems to be the case also for the basic law of life science-the law of self-replication.

Why can a pea reproduce (replicate) new peas? Why can a bacterial cell reproduce (replicate) new cells? This is a difficult problem that has long puzzled life scientists and philosophers. But few thought it could be so simple: the answer is almost a tautology.

To understand this problem, all we must do is first realize what life (organism) replication is, and then we must look for its cause, to ultimately discover the law of self-replication. This is the key to unlocking the secrets of life.

\section{Life (Organism) Replication}

There are many so-called replication or copying processes in the world, such as 
file replication, photocopying, film copying, building clones, and machine clones; however, these do not constitute life (organism) replication. Then, what is life (organism) replication? Life (organism) replication has the following features.

\subsection{Life Replication Is Accomplished by Itself}

File replication is performed by a copyist or printer, photocopying or film copying is done by a copy-machine; a building's clone is built by workers with their equipment-aircraft can't reproduce aircraft; tanks can't reproduce tanks-none of these can accomplish their own replication. Only organisms can accomplish replication by themselves: peas reproduce peas, melons replicate melons, and cells of Escherichia coli replicate cells of E. coli.

\subsection{Life Replication Should Be Called Replication of All Components, in Which Every Chemical Component of the Organism Is Replicated}

We can explain this using E. coli cells as an example. We know that one bacterial cell can reproduce into two bacterial cells. We can express this as " 1 cell $\rightarrow 1$ cell", reading " $\rightarrow$ " as "produces".

During the process of " 1 cell $\rightarrow 1$ cell", one cell becomes two cells. This is a fact of cell replication. A cell is formed by its chemical substances. Here, one set of bacterial substances becomes two sets when " 1 cell $\rightarrow 1$ cell". That is to say, each cell of a clone contains the same components if the bacterial living environment remains unchanged. Such replication is the replication of all components. We provide four commonly known facts to support this statement. 1) All biological materials (such as penicillin, insulin, tuberculin) are renewable. 2) The material composition of each cell from a clone should be the same. 3) If a scientist discovered that a certain bacterium could produce a new material (such as colicin), scholars all over the world would attempt to repeat such a finding. Such a finding must be able to be repeated in this bacterium's clonal offspring; otherwise the findings would not be accepted. 4) From molecular biology textbooks, we know that the materials of a cell can be summarized as follows: first class, the components of transcription, i.e., DNA (genome) and transcription system materials; second, the direct products of transcription undertaken as a collaboration between the DNA template and the transcription system (the operator of transcription), namely RNA (including mRNA, rRNA, and tRNA); third, RNA-translation products, i.e., proteins (including enzymes); fourth, enzymatic products (such as carbohydrates and lipids). Because the materials of the first class (the genome and transcription systems) are fixed, their direct and indirect products, i.e., the second, third, and fourth classes, will also be fixed if the living environment remains constant.

\subsection{Life Replication Is Replication with Decreasing Entropy [1]}

Every individual, cell, and even organic polymer molecule has lower entropy 
than the total entropy of its raw materials; therefore no organism could be produced unless its producer consumes energy and does work. In other words, all productions that do not consume energy and do not work can never be life productions. Similarly, replications that consume no energy and do not work can never be life replications.

\section{The Law of Self-Replication}

From life replication we can derive the basic law of life science: the law of self-replication.

Now let us prove it.

It is known that a cell can produce a cell, i.e., "cell $\rightarrow$ cell" (or one cell becomes two cells). This is the replication of the cell.

A cell is formed by its chemical components, so the replication of the cell means firstly the replication of cell's components.

We use $\Sigma \mathrm{A}$ to represent a set of components of the cell above, i.e., $\Sigma \mathrm{A}=\mathrm{A}_{1}$, $\mathrm{A}_{2}, \mathrm{~A}_{3} \cdots \mathrm{A}_{\mathrm{x}} \cdots \mathrm{A}_{\mathrm{n}}$.

" $A$ " should be read as the "cell's chemical component(s)". We give every " $A$ " a serial number: $1,2,3 \cdots \mathrm{x} \cdots \mathrm{n}$; the total number of them is $\mathrm{n}$, and $\mathrm{x}$ represents any positive integer less than $n$.

Thus, replication of all the components can be expressed as $\Sigma A \rightarrow \Sigma A$, i.e., $A_{1}$, $A_{2}, A_{3} \cdots A_{x} \cdots A_{n} \rightarrow A_{1}, A_{2}, A_{3} \cdots A_{x} \cdots A_{n}$.

Here we cannot judge if the producer is directly the entire $\Sigma A$. We can judge only that the producer must be within $\Sigma \mathrm{A}$. We use $\Delta \mathrm{A}$ to represent this unknown producer, namely $\Sigma A \rightarrow \Sigma A$ is really $\Delta A \rightarrow \Sigma A$. $\Delta A$ may be one " $A$ " (e.g., $A_{1}$ or $A_{x}$ ), two " $A$ " (e.g., $A_{1}, A_{x}$, or $A_{3}, A_{x+1}$ ), three " $A$ " (e.g., $A_{1}, A_{7}, A_{11}$, or any other three " $A$ "), four " $A$ " ...x" $A$ "......even n" $A$ " (i.e., $\Sigma A$ ). However, $\Delta A \rightarrow \Sigma A$ is equal to $\Delta \mathrm{A} \rightarrow \Delta \mathrm{A}+(\Sigma \mathrm{A}-\Delta \mathrm{A})$, namely $\Delta \mathrm{A} \rightarrow \Delta \mathrm{A}$ and $\Delta \mathrm{A} \rightarrow(\Sigma \mathrm{A}-\Delta \mathrm{A})$. Here $\Delta \mathrm{A} \rightarrow \Delta \mathrm{A}$ indicates that $\Delta \mathrm{A}$ can produce $\Delta \mathrm{A}$ itself. That is to say, $\Delta \mathrm{A}$ (namely producer) is a self-replicate substance(s).

We can express the proof process simply as follows:

It is known that cell $\rightarrow$ cell.

This must be based on $\Sigma \mathrm{A} \rightarrow \Sigma \mathrm{A}$.

However, $\Sigma \mathrm{A} \rightarrow \Sigma \mathrm{A}$ is really $\Delta \mathrm{A} \rightarrow \Sigma \mathrm{A}$.

Equally, " $\Delta \mathrm{A} \rightarrow \Sigma \mathrm{A}$ " is equal to " $\Delta \mathrm{A} \rightarrow \Delta \mathrm{A}+(\Sigma \mathrm{A}-\Delta \mathrm{A})$ ".

Therefore, we arrive at $\Delta \mathrm{A} \rightarrow \Delta \mathrm{A}$, with $\Delta \mathrm{A} \rightarrow(\Sigma \mathrm{A}-\Delta \mathrm{A})$.

Finally, according to $\Delta \mathrm{A} \rightarrow \Delta \mathrm{A}$ we can affirm that $\Delta \mathrm{A}$ is a self-replicate substance(s).

Thus, we obtain the law of self-replication expressing as following:

Anything that is able to replicate all its own (chemical) components is created by self-replicating substance(s). In other words, self-replicating substance(s) is (are) the root cause of living things arising. Without self-replicating substance(s), no living things could arise in the world.

Therefore, we can define living things as self-replicating things which could only be created and developed by self-replicating substance(s); having life exactly 
is having the ability of self-replicating, so the life is the ability to replicate itself. This is the definition for life. Of course, the producing for replicating here should meet the requirements of reducing entropy producing said before by us.

This principle of the law of self-replication is simple and undeniable. Let us imagine. For example, there were 10 prisoners breaking out of jail. We can judge that, among the 10 men, there must be at least one instigator of this incident, and this could be one, two, three, or even all 10 of the prisoners.

So we get: instigator $\rightarrow 10$ men (out of jail). However, "instigator $\rightarrow 10$ men" is equal to "instigator $\rightarrow$ instigator + (10 men - instigator)".

That is to say, the instigator(s) gets not only himself (or themselves) out of jail but also the others (10 men - instigator).

Therefore, the law of jail-breaking is: the person breaking himself out of jail is the root cause of any jail-breaking occurrence. Without such person(s), there will be no jail-breaking.

Recently, I have found an even simpler method of proof.

It is known that cell $\rightarrow$ cell. This suggests that $\Sigma \mathrm{A} \rightarrow \Sigma \mathrm{A}$ should exist first.

This expression tells us that, within $\Sigma \mathrm{A}$, there must be a producer able to produce $\Sigma$ A.

So, the producer must be able to replicate itself, because itself is a part (or all) of $\Sigma$ A.

This also holds true for the law of jail-breaking: 10 prisoners breaking out of jail are known. That means that some or all of the 10 men instigated the incident. Thus, the instigator must break himself out of jail, because the instigator is a part (or all) of these 10 men. So such person(s) is the root cause of any jail-breaking occurrence.

\section{The Law of Self-Replication Is the Key to Unlocking the Secrets of Life}

Because all the materials of an organism are the products of this organism's self-replicating material, the following truths exist: 1) the self-replicating material determines what materials (and therefore, characteristics) an organism can have; and 2) without new self-replicating material there would be no new individual (i.e. offspring). Consequently, the self-replicating material must first be passed from parent(s) to offspring, and become the physical basis of new individual arising; in other words, it is the hereditary material of living things. That is to say, the producer of living things, the self-replicating material and the hereditary material all three are the same object.

Moreover, it is imaginable that the law of self-replication could provide a starting point to explore the origin of life.

\section{Acknowledgements}

The author thanks Rebecca Devon, Ph.D., from Liwen Bianji, Edanz Group, China (http://www.liwenbianji.cn/ac), for editing the English text of a draft of 
this manuscript.

\section{References}

[1] Schrödinger, E. (1944) What Is Life-The Physical Aspect of the Living Cell. Cambridge University Press, Cambridge. 